\title{
Evaluation of Antioxidant and Antibacterial Effects of PLGA Nanoparticles Loaded with Rapeseed Pollen Extract
}

\author{
Hanieh Shabestarian', Masoud Homayouni Tabrizi ${ }^{* r}$, Ali Eshaghir
}

Received 25 Apr 2021, Accepted for publication 11 Sep 2021

\begin{abstract}
Background \& Aims: In this study, the antioxidant and antibacterial capacity of PLGA nanoparticles containing rapeseed extract (REPNP) was investigated.

Materials \& Methods: Three various methods including Disk Diffusion(DD), Minimal Inhibitory Concentration (MIC), and Minimum Bactericidal Concentration (MBC) were used to evaluate the antibacterial effects of synthesized nanoparticles against different strains of bacteria. The inhibition capacity of ABTS and DPPH free radicals was measured to evaluate the antioxidant power of RE-PNP.
\end{abstract}

Results: The results showed that the RE-PNP have the potential to inhibit DPPH radicals $\left(\mathrm{IC}_{50}=500 \mu \mathrm{g} / \mathrm{ml}\right)$ and $\mathrm{ABTS}_{(\mathrm{IC}} 5_{0}=1000 \mu \mathrm{g}$ / ml). The inhibitory effect of RE-PNP on the growth of Staphylococcus aurous and Micrococcus luteus was confirmed by the growth inhibition zone 8 and 15 in the disk diffusion model.

Conclusion: According to the results, RPE-PNPS can be used as a safe, natural, and effective antibiotic for bacterial infections caused by Staphylococcus aureus and Micrococcus luteus and also, this formulation can be used due to its antioxidant effects in treatment of oxidative stress-related diseases.

Keywords: PLGA nanoparticle, Rapeseed pollen, ABTS, DPPH, Disk Diffusion test, Minimal inhibitory concentration (MIC), Minimum Bactericidal concentration (MBC)

Address: Department of Biology, Mashhad Branch, Islamic Azad University, Mashhad, Iran

Tel: +9838435050

Email: mhomayouni6@gmail.com and mhomayouni6@mshdiau.ac.ir

\section{Introduction}

Herbs and their natural products are sources with active healing properties that are used not only as medicine, but also as unique patterns to start making synthetic analogues(1). In recent years, the use of herbal medicines to control diseases, especially infectious diseases, has increased due to their low side effects compared to chemical drugs (2). Increasing awareness of the benefits of natural compounds with therapeutic properties and the desire of researchers to use these compounds have led to their widespread use in medicine and treatment. Studies have shown that many of the antioxidant and antimicrobial properties of plant extracts are due to the presence of substances such as phenol, flavonoids, and similar compounds(3). Previous studies have examined and confirmed the antioxidant

\footnotetext{
${ }^{1}$ Department of Biology, Mashhad Branch, Islamic Azad University, Mashhad, Iran

${ }^{2}$ Department of Biology, Mashhad Branch, Islamic Azad University, Mashhad, Iran (Corresponding author)

${ }^{3}$ Department of Biology, Mashhad Branch, Islamic Azad University, Mashhad, Iran
} 
and antibacterial effects of some plant extracts (4-8). One of the new approaches to increase the biological effects and stability of natural compounds as well as increasing their solubility and transfer is the use of nanocarriers. The use of therapies based on nanostructured drug delivery systems is of great importance in the prevention and treatment of infections due to the proper and continuous release of drugs to establish the appropriate concentration of drugs in the blood and tissues to treat infectious diseases (9). Today, synthetic polymers and natural macromolecules are widely used as colloidal materials to produce and design nanoparticles for drug delivery. Among synthetic polymers, polyesters such as polylactic-glycolic poly (PLGA) are more important in the field of medical biology due to their biocompatibility and biodegradability(10). Biodegradable compounds are degraded in vitro enzymatically or non-enzymatically or both, producing biocompatible, non-toxic, and safe products that are eliminated by normal metabolic pathways. Therefore, the human body interacts effectively with these monomers (Lactic and glycolic acid monomers), these compounds are metabolized through the tricarboxylic acid (TCA) cycle, hence PLGA has been approved by the FDA and it is used in the medical system (11). Therefore, in this study, for the first time, the antibacterial and antioxidant effects of RPE-PNPs were evaluated.

\section{Materials \& Methods}

\subsection{Antibacterial effects of RPE-PNPs}

\subsubsection{Disk Diffusion assay (DD)}

In order to evaluate the antimicrobial effect of RPEPNPs, Disk diffusion by the Kirby-Bauer method was used. Cultures of Staphylococcus aureus ATCC 1112, Micrococcus luteus PTCC 1408, Pseudomonas aeruginosa ATCC 1074, and Escherichia coli ATCC 1330 were cultivated on Mueller-Hinton agar plates, separately. Bacteria samples from one or two overnight grown colonies were suspended in a test tube containing nutrient broth. The turbidity (expressed as optical density; OD) of the bacterial suspensions were measured with an optical spectrophotometer $(\lambda=600 \mathrm{~nm})$ and adjusted to 0.25 or 0.50 . A sterile swab was immersed in the resulting suspension and applied to the agar medium. Rapeseed pollen extract, aqueous extract of rapeseed pollen, and RPE-PNPs (3 mg per disk) were loaded onto the disks in a volume of $10 \mu \mathrm{l}$ and the samples were incubated at $37^{\circ} \mathrm{C}$ for 24 hours. Inhibition zones around the disks were measured according to the Kirby-Bauer test protocol. Gentamicin $(10 \mu \mathrm{g} / \mathrm{ml})$ was used as a positive control (12).

2.1.2. Minimal Inhibitory concentration (MIC) and Minimum Bactericidal Concentration (MBC)

In order to determine MIC and $\mathrm{MBC}$, microbroth dilution method was used. In this method, 24 and 96 well microplates were used. Extracts of rapeseed, aqueous extract of rapeseed, and RPE-PNPs were prepared with concentrations of 0 to $5 \mathrm{mg} / \mathrm{ml}$, and chloramphenicol antibiotic powder with a concentration of $100 \mu \mathrm{g} / \mathrm{ml}$ was used as a control. After inoculating the bacteria in the wells, the microplate was incubated for 24 hours at $37^{\circ}$ C. After incubation, the first bacterial growth-free well was considered as the minimum concentration of growth inhibitor (MIC). From this dilution and higher dilutions, $10 \mu \mathrm{l}$ were transferred to the nutrient agar medium. The concentration that was free of bacterial growth was considered as the minimum lethal growth concentration $(\mathrm{MBC})(13)$.

\subsection{Antioxidant effects of RPE-PNPs}

\subsubsection{ABTS scavenging free radicals}

To do this, ABTS free radicals must first be produced through the oxidation of ABTS by potassium persulfate. First, ABTS $7 \mathrm{mM}$ was prepared and then potassium sulfate was added to it, the resulting solution was incubated for 16 hours in the dark at room temperature and then diluted 40 times. The resulting solution was used as a working solution to evaluate the inhibitory power of nanoparticles. For this purpose, 
different concentrations of RPE-PNPs (with a volume of $500 \mu \mathrm{l})$ were prepared and then equal volume of free radical solution was added to each and the adsorption of the samples was measured at a wavelength of $734 \mathrm{~nm}$. Blank PLGA nanoparticles with ethanol were used as negative control and glutathione as positive control. The formulas used are: Free radical scavenging percentage ABTS $=$ OD control - OD sample / OD control $\times$ 100(14).

\subsubsection{DPPH scavenging free radicals}

In order to evaluate the free radical scavenging power of DPPH by RPE-PNPs, first DPPH free radicals were produced by dissolving $1 \mathrm{mg}$ of DPPH powder in $17 \mathrm{ml}$ of ethanol and then $500 \mu \mathrm{l}$ of different concentrations of RPE-PNPs were prepared and mixed with equal volumes of DPPH free radicals. Blank PLGA nanoparticles with ethanol were used as negative control and glutathione as positive control. The results of this study were expressed as $\mathrm{IC}_{50}$, which indicates the concentration of RPE-PNPs that can inhibit $50 \%$ of free radicals.

The formulas used are: Free radical scavenging percentage $\mathrm{DPPH}=\mathrm{OD}$ control - OD sample / OD control $\times 100(14)$.

\begin{tabular}{|c|c|c|c|c|}
\hline $\begin{array}{c}\text { Micrococcus luteus } \\
\text { ATCC 1408 }\end{array}$ & $\begin{array}{c}\text { Staphylococcus aurous } \\
\text { ATCC 1112 }\end{array}$ & $\begin{array}{c}\text { Pseudomonas aeruginosa } \\
\text { ATCC 1074 }\end{array}$ & $\begin{array}{c}\text { Escherichia coli } \\
\text { ATCC 1330 }\end{array}$ & \begin{tabular}{c} 
Rapeseed pollen \\
\hline 8
\end{tabular} \\
\hline 0 & 0 & 0 & 0 & $\begin{array}{c}\text { Aqueous extract } \\
\text { of rapeseed pollen }\end{array}$ \\
\hline 15 & 0 & 0 & $\begin{array}{c}\text { PLGA-rapeseed } \\
\text { pollen extract }\end{array}$ \\
\hline Gentamicin
\end{tabular}

than rapeseed extract alone.

\subsection{Statistical analysis}

Data were analyzed using SPSS software version 22 using one-way ANOVA and LSD test. Each experiment was triplicated and the results were expressed in mean of \pm SD. Significance of data was considered at the level of $* \mathrm{p}<0.05, * * \mathrm{p}<0.01$ and $* * * \mathrm{p}<0.001$.

\section{Results}

\subsection{Antibacterial effects of RPE-PNPs}

\subsubsection{Disk Diffusion test (DD)}

Rapeseed extract had a growth inhibitory effect only against Micrococcus luteus $(8 \mathrm{~mm})$. Aqueous extract of rapeseed pollen had no growth inhibitory effect on any of the bacterial strains. The RPE-PNPs showed a stronger bacteriostatic effect by creating inhibition zone of $8 \mathrm{~mm}$ on Staphylococcus aurous and $15 \mathrm{~mm}$ in Micrococcus luteus culture. The diameter of the growth inhibition zone in the presence of gentamicin antibiotic for Staphylococcus aureus, Pseudomonas aeruginosa, Escherichia coli, and Micrococcus luteus bacteria were $12,18,19$, and $37 \mathrm{~mm}$, respectively. The data show that RPE-PNPs have higher inhibitory effects on Staphylococcus aureus and Micrococcus luteus bacteria

Figure 1. The disk diffusion assay. Comparison of bacterial inhibition of rapeseed extract, aqueous extract of rapeseed pollen, RPE-PNPs, and gentamicin antibiotic in Disk Diffusion method. 


\subsubsection{Minimal inhibitory concentration (MIC)}

After incubation at $37^{\circ} \mathrm{C}$, turbidity was not observed in the Staphylococcus aureus culture medium treated with rapeseed pollen and only Micrococcus luteus bacteria was grown at a concentration of $0.25 \mathrm{mg} / \mathrm{ml}$
RPE-PNPs. 24 hours after RPE-PNP treatment at $37^{\circ}$ $\mathrm{C}$, turbidity was observed at concentrations of $3 \mathrm{mg} / \mathrm{ml}$ (for Micrococcus luteus) and $5 \mathrm{mg} / \mathrm{ml}$ (for Staphylococcus aureus) indicating the bacterial growth in this concentrations.

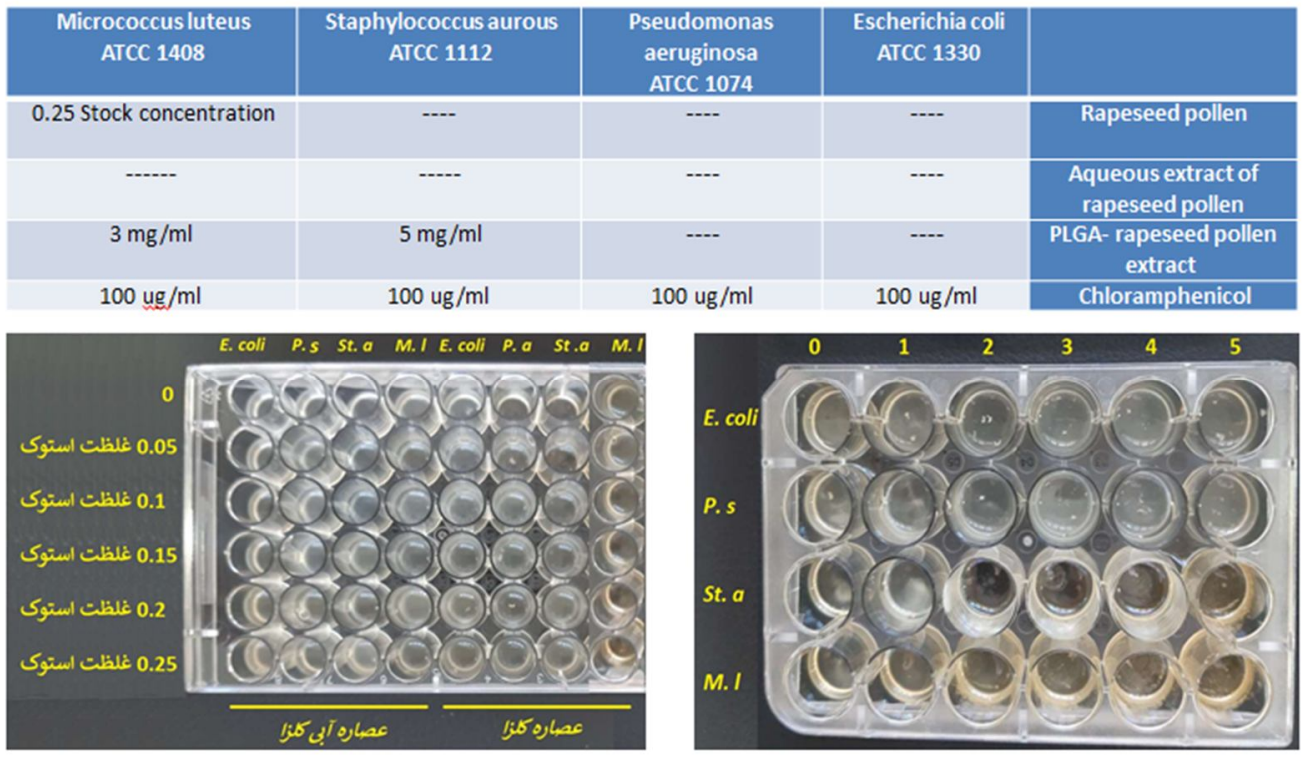

Figure 2. Minimal inhibitory concentration (MIC) assay. Comparison of bacterial inhibition of rapeseed extract, aqueous extract of rapeseed pollen, RPE-PNPs and gentamicin antibiotic in Minimal inhibitory concentration (MIC).

\subsubsection{Minimum Bactericidal concentration (MBC)}

According to the results, rapeseed pollen extract and aqueous extract of rapeseed pollen had no lethal effect on bacterial strains, while RPE-PNPs at a concentration of $5 \mathrm{mg} / \mathrm{ml}$ had a lethal effect against Micrococcus luteus.

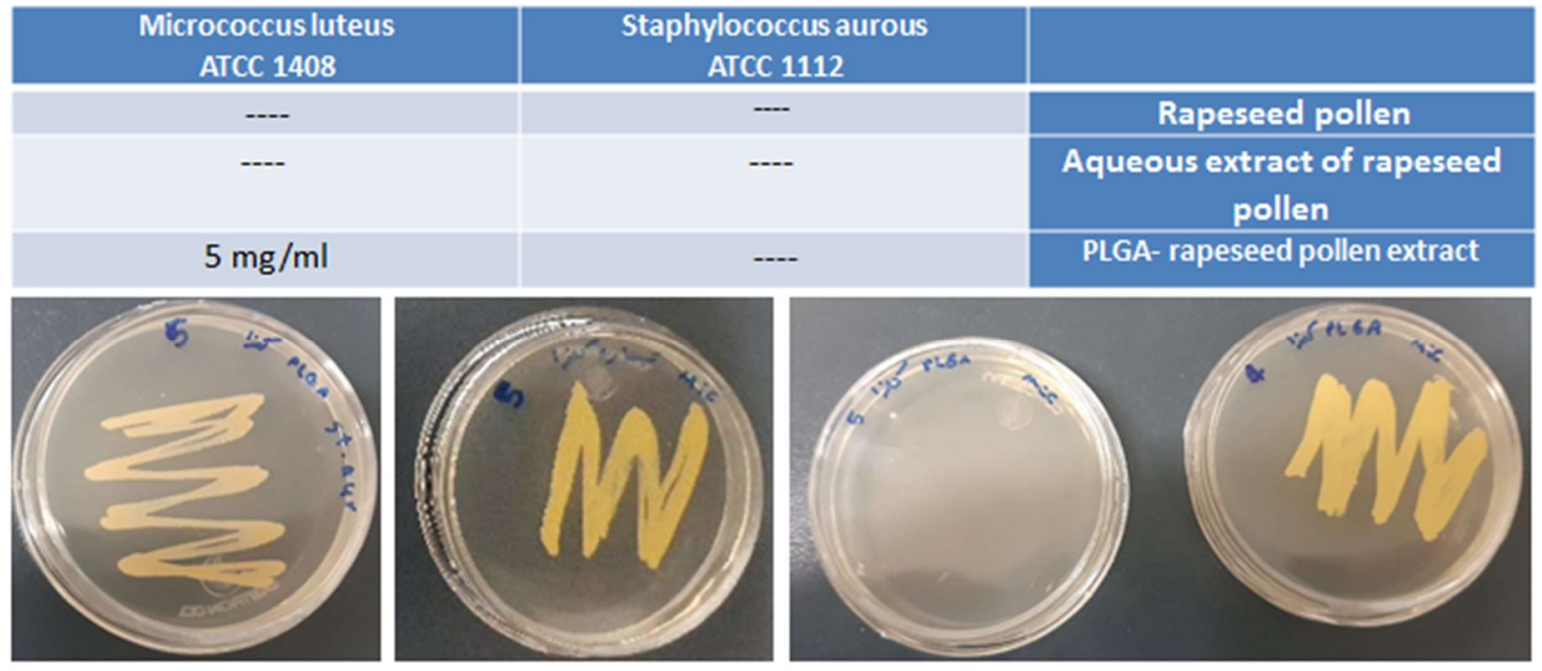

Figure 3. Minimum Bactericidal concentration (MBC) assay. The results reported a MBC of RPE-PNPs on the Micrococcus luteus strain of about $5 \mathrm{mg} / \mathrm{ml}$. 


\subsection{Antioxidant effects of RPE-PNPs}

\subsubsection{ABTS scavenging free radicals}

Examination of ABTS free radical scavenging in the presence of RPE-PNPs showed that the degree of inhibition is dose dependent and by increasing the concentration from 62.5 to $1000 \mu \mathrm{g} / \mathrm{ml}$ the inhibition rate increases from $7 \%$ to $45.26 \%$. Comparison of ABTS and DPPH radical scavenging showed higher inhibitory effect of RPE-PNPs on DPPH free radicals.

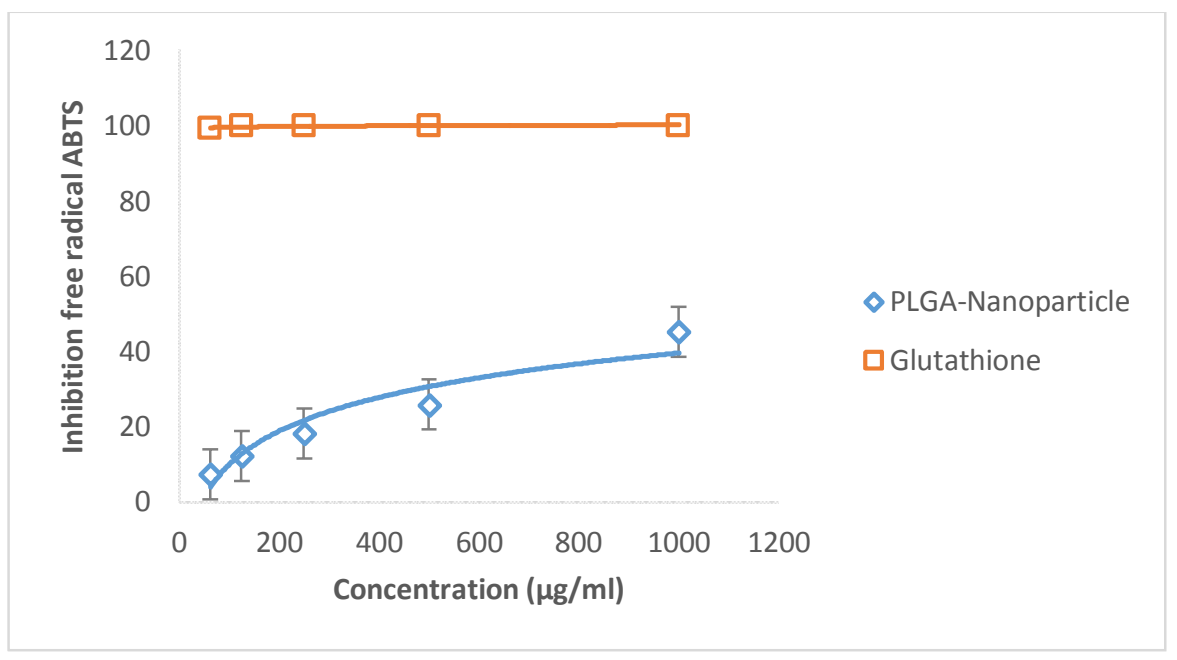

Figure 4. ABTS scavenging assay. Increased free radical scavenging of ABTS exposed to different concentrations of RPE-PNPs compared to glutathione as an antioxidant compound.

\subsubsection{DPPH scavenging free radicals}

The results reported an increase in the rate of DPPH free radicals inhibition while increasing concentration of RPE-PNPs. The rate of free radical scavenging at a concentration of $100 \mu \mathrm{g} / \mathrm{ml}$ was about $5 \%$ and by increasing the concentration to $500 \mu \mathrm{g} / \mathrm{ml}$ the rate of inhibition increased to $52 \%$, indicating the effectiveness of the concentration factor on inhibitory effect of RPEPNPs.

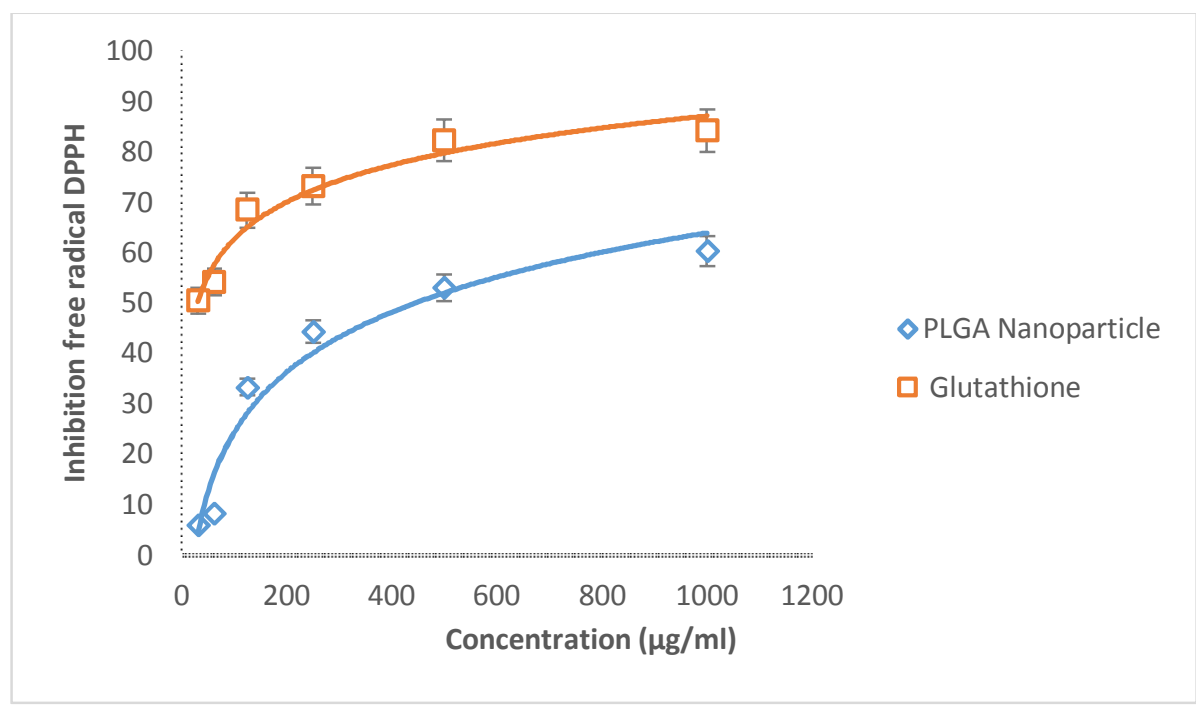

Figure 5. DPPH scavenging assay. Increased free radical scavenging of DPPH exposed to different concentrations of RPE-PNPs compared to glutathione as an antioxidant compound. 


\section{Discussion}

In this study, the antioxidant properties of RPEPNPs on DPPH and ABTS free radicals and the susceptibility of Staphylococcus aureus, Pseudomonas aeruginosa, Micrococcus luteus, and Escherichia coli to RPE-PNPs were evaluated. The results of studies have shown that plant extracts due to their secondary metabolites such as glycosides, alkaloids, terpenoids, phenolics, and coumarins have various biological effects including antibacterial, antioxidant, etc. (3). In various studies, the antioxidant and antibacterial effects of various extracts have been investigated and confirmed. In a study conducted in 2000 , the antioxidant and antibacterial effects of clove extract were investigated and confirmed. Similarly, other studies have reported the antioxidant and antibacterial effects of extracts of clove(15), Portulaca(16), Tribulus(17), Eryngium(18), Turmeric(19, 20), Ginger(21), Thyme(22, 23), Pennyroyal(24), Fennel(25), Chamomile(25), Mint(26), Burdock(27), Eucalyptus(28), Primrose(29), Lemon balm(30), Mallows(31), Garlic (32), and cinnamon(33, 34). Examination of the antibacterial effect of Tribulus extract showed that this compound can have a high bacteriostatic effect against $E$. faecali, S. aureus, $P$. aeruginosa, and E. coli strains at a concentration of 2 $\mathrm{mg} / \mathrm{ml}$ (35). Similarly clove extract at a concentration of $62.5 \mathrm{mg} / \mathrm{ml}$ showed a high inhibitory effect against $S$. aureus (36). The results of other studies also reported the inhibitory effect of mint and garlic extract against $E$. coli at a concentration of $64 \mu \mathrm{g} / \mathrm{ml}(37)$ and 0.075 $\mathrm{mg} / \mathrm{ml}(38)$, respectively. Inhibition of ABTS free radicals by extracts of Tribulus(39), Cinnamon(40), clove(41), and inhibition of DPPH free radicals by extracts of Portulaca(42), Eryngium(43), Ginger(44), Thyme(45), etc. have been reported in the results of previous studies. In spite of all the activities of plant compounds and extracts, their use has limitations. Today, the use of nanocarriers to increase the effectiveness of bioactive compounds has received much attention and many Nano carriers are used to deliver drugs and increase the bioavailability of active compounds (46). In this study, PLGA Nano polymer was used as a carrier for rapeseed pollen extract and its biological effects were examined. In a study conducted in 2019, rapeseed pollen extract was used to synthesize silver nanoparticles and its antioxidant effects were investigated. The results showed that the synthesized nanoparticles were able to inhibit ABTS and DPPH free radicals with $\mathrm{IC}_{50}$ about 800 and $830 \mu \mathrm{g} / \mathrm{ml}$, respectively(47) which is comparable and similar to the results of the present study in antioxidant capacity. The results of the inhibitory effect of zinc oxide nanoparticles synthesized with rapeseed pollen extract reported a moderate concentration of about 3 and 6 $\mu \mathrm{g} / \mathrm{ml}$ to inhibit ABTS and DPPH free radicals, indicating the very high antioxidant effects of the synthesized nanoparticles(48). Different inhibitory effect of nanoparticles synthesized from rapeseed extract on free radicals can be related to the type of nanoparticles and their synthesis methods.

In another study, the antioxidant and antibacterial effects of Thymoquinone loaded on PLGA polymers were investigated and the results showed that the synthesized nanoparticles were able to inhibit $70 \%$ of DPPH free radicals at a concentration of $1 \mathrm{mg} / \mathrm{ml}$, and this amount of inhibition is comparable and similar to the results of the present study. Similarly, Thymoquinone-PLGA also exhibited antibacterial properties against E. coli, Staphylococcus aureus, and Salmonella typhi strains with inhibition zone of 6,7 , and $7 \mathrm{~mm}$, respectively (49). Comparison of the results shows that RPE-PNPs have an inhibitory effect on grampositive bacteria and no inhibitory effect was observed in the studied gram-negative bacteria, while the inhibitory effect of Thymoquinone-PLGA on both gram-positive and gram-negative bacteria was reported. 
Similar to the present study, the results of a study conducted in 2017 confirmed the antioxidant effect of PLGA loaded with guabiroba fruit phenolic extract (50).

\section{Conclusion}

The antioxidant potential of RPE-PNPs inhibit ABTS and DPPH free radicals and inhibit the growth of Staphylococcus aureus and Micrococcus luteus confirms the therapeutic effects of RPE-PNPs and these properties make this formulation an attractive option for clinical studies.

\section{Acknowledgments}

The authors appreciate the support of the Islamic Azad University, Mashhad, Iran in conducting the present research.

\section{Funding}

This research received no specific grant from any funding agency in the public, commercial, or not-forprofit sectors.

\section{References}

1. Reid KA, Jäger AK, Light ME, Mulholland DA, Van Staden J. Phytochemical and pharmacological screening of Sterculiaceae species and isolation of antibacterial compounds. J Ethnopharmacol 2005;97(2):285-91.

2. Avijgan M, Saadat M, Nilfrooshzadeh MA, Hafizi M. Anti fungal effect of Echinophora platyloba extract on some common dermathophytes. J Med Plants 2006; 5(18): 10-6.

3. Parham S, Kharazi AZ, Bakhsheshi-Rad HR, Nur H, Ismail AF, Sharif S, et al., Antioxidant, Antimicrobial and Antiviral Properties of Herbal Materials. Antioxidants 2020; 9(12): 1309.

4. El-Maati MF, Labib SM, Al-Gaby AM, Ramadan MF.Antioxidant properties of different extracts from five medicinal plants. Zag J Agric Res 2012; 39: 1-13.

5. Stagos D. Antioxidant activity of polyphenolic plant extracts. Antioxidants (Basel) 2019;9(1):19.
6. Liu X, Jia J, Jing X, Li G. Antioxidant activities of extracts from sarcocarp of Cotoneaster multiflorus. Journal of Chemistry 2018; 2018.

7. Safari, M. and S. Ahmady-Asbchin, Evaluation of antioxidant and antibacterial activities of methanolic extract of medlar (Mespilus germanica L.) leaves. Biotechnol Biotechnol Equip 2019; 33(1): 372-8.

8. Islam MZ, Hossain MT, Hossen F, Mukharjee SK, Sultana N, Paul SC. Evaluation of antioxidant and antibacterial activities of Crotalaria pallida stem extract. Clinical Phytoscience 2018; 4(1): 1-7.

9. Campoccia D, Montanaro L, Speziale P, Arciola CR. Antibiotic-loaded biomaterials and the risks for the spread of antibiotic resistance following their prophylactic and therapeutic clinical use. Biomaterials 2010; 31(25): 636377.

10. Astete CE, Sabliov CM. Synthesis and characterization of PLGA nanoparticles. J Biomater Sci Polym Ed 2006; 17(3): 247-89.

11. Jagur-Grodzinski J. Biomedical application of functional polymers. Reactive \& Functional Polymers 1999; 39(2): 99-138.

12. Kourmouli A, Valenti M, van Rijn E, Beaumont HJ, Kalantzi OI, Schmidt-Ott A, et al .Can disc diffusion susceptibility tests assess the antimicrobial activity of engineered nanoparticles? J Nanopart Res 2018; 20(3): 16.

13. Gaydos JM, Harrington BJ. Agar disk diffusion for the quality control testing of Autobac elution disks. Antimicrob Agents Chemother1982; 21(3): 516-8.

14. Khatamian N, Homayouni Tabrizi M, Ardalan P. Effect Of Carum Carvi Essential Oil Nanoemulsion On Tubo Cancer Cells And L929 Normal Cells And Evaluation Of Antioxidant Activity. Stud Med Sci 2019; 30(4): 315-21.

15. Anwer MK, Jamil S, Ibnouf EO, Shakeel F. Enhanced antibacterial effects of clove essential oil by nanoemulsion. J Oleo Sci 2014;63(4):347-54. 
16. Zhou YX, Xin HL, Rahman K, Wang SJ, Peng C, Zhang H. Portulaca oleracea L.: a review of phytochemistry and pharmacological effects. Biomed Res Int. 2015;2015:925631.

17. Tian C, Chang Y, Zhang Z, Wang H, Xiao S, Cui C, et al. Extraction technology, component analysis, antioxidant, antibacterial, analgesic and anti-inflammatory activities of flavonoids fraction from Tribulus terrestris L. leaves. Heliyon 2019; 5(8): e02234.

18. Soumia B. Eryngium campestre L.: Polyphenolic and flavonoid compounds; Applications to health and disease. Polyphenols: Mechanisms of Action in Human Health and Disease 2018:69-79.

19. Sharma S, Ghataury SK, Sarathe A, Dubey G, Parkhe G.Curcuma angustifolia Roxb,(Zingiberaceae): Ethnobotany, phytochemistry and pharmacology: A review. J Pharmacogn Phytochem 2019; 8: 1535-40.

20. Panpatil VV, Tattari S, Kota N, Nimgulkar C, Polasa K. In vitro evaluation on antioxidant and antimicrobial activity of spice extracts of ginger, turmeric and garlic. Journal of Pharmacognosy and phytochemistry 2013; 2(3): 143-18.

21. Idris NA, Yasin HM, Usman A. Voltammetric and spectroscopic determination of polyphenols and antioxidants in ginger (Zingiber officinale Roscoe). Heliyon 2019; 5(5): e01717.

22. Oliviero M, Romilde I, Beatrice MM, Matteo V, Giovanna N, Consuelo A, et al. Evaluations of thyme extract effects in human normal bronchial and tracheal epithelial cell lines and in human lung cancer cell line. Chem Biol Interact 2016; 256: 125-33.

23. Tzima K, Makris D, Nikiforidis CV, Mourtzinos I.Potential use of rosemary, propolis and thyme as natural food preservatives. J Nutr Health 2015; 1(6).

24. Miraj S, Kiani S. Study of pharmacological effect of Mentha pulegium: A review. Der Pharmacia Lettre 2016; 8(9): 242-5.

25. Rajić JR, Đorđević SM, Tešević V, Živković MB, Đorđević NO, Paunović DM, et al. The extract of fennel fruit as a potential natural additive in food industry. Journal of Agricultural Sciences 2018; 63(2): 205-15.

26. Mimica-Dukic N, Bozin B.Mentha L .species (Lamiaceae) as promising sources of bioactive secondary metabolites. Curr Pharm Des 2008; 14(29): 3141-50.

27. Fierascu RC, Georgiev MI, Fierascu I, Ungureanu C, Avramescu SM, Ortan A, et al. Mitodepressive, antioxidant, antifungal and anti-inflammatory effects of wild-growing Romanian native Arctium lappa L.(Asteraceae) and Veronica persica Poiret (Plantaginaceae). Food Chem Toxicol 2018;111:44-52.

28. Luís Â, Neiva DM, Pereira H, Gominho J, Domingues F, Duarte AP. Bioassay-guided fractionation, GC-MS identification and in vitro evaluation of antioxidant and antimicrobial activities of bioactive compounds from Eucalyptus globulus stump wood methanolic extract. Industrial Crops and Products 2016; 91: 97-103.

29. Munir R, Semmar N, Farman M, Ahmad NS. An updated review on pharmacological activities and phytochemical constituents of evening primrose (genus Oenothera). Asian Pac J Trop Biomed 2017; 7(11): 1046-54.

30. Miraj S, Azizi N, Kiani S.A review of chemical components and pharmacological effects of Melissa officinalis L. Der Pharmacia Lettre 2016; 8(6): 229-37.

31. Paul D. A review on biological activities of common Mallow (Malva sylvestris L.). J Life Sci 2016;4:1-5.

32. Toledano Medina MÁ, Merinas-Amo T, FernándezBedmar Z, Font R, Del Río-Celestino M, Pérez-Aparicio J, et al., Physicochemical characterization and biological activities of black and white garlic: In vivo and in vitro assays. Foods 2019; 8(6):220.

33. Friedman M, Henika PR, Mandrell RE. Bactericidal activities of plant essential oils and some of their isolated constituents against Campylobacter jejuni, Escherichia coli, Listeria monocytogenes, and Salmonella enterica. J Food Prot 2002; 65(10): 1545-60.

34. Willis S, Sunkara R, Hester F, Shackelford L, Walker LT, Verghese M. Chemopreventive and anti-inflammatory potential of select herbal teas and cinnamon in an in-vitro 
cell model. Food and Nutrition Sciences 2019; 10(9): $1142-56$

35. Kianbakht S, Jahaniani F. Evaluation of antibacterial activity of Tribulus terrestris L. growing in Iran. Iranian Journal of Pharmacology and Therapeutics 2003; 2 (1) $: 22$.

36. Gupta C, Garg AP, Uniyal RC, Kumari A. Comparative analysis of the antimicrobial activity of cinnamon oil and cinnamon extract on some food-borne microbes. Afr $\mathrm{J}$ Microbiol Res 2008; 2(9): 247-51.

37. Bor T, Aljaloud SO, Gyawali R, Ibrahim SA. Antimicrobials from herbs, spices, and plants. In: Fruits, vegetables, and herbs. Elsevier; 2016. p. 551-78.

38. Petropoulos S, Fernandes Â, Barros L, Ciric A, Sokovic M, Ferreira ICFR. Antimicrobial and antioxidant properties of various Greek garlic genotypes. Food Chem 2018; 245: 7-12.

39. Zheleva-Dimitrova D, Obreshkova D, Nedialkov P.Antioxidant activity of tribulus terrestris - a natural product in infertility therapy. Int J Pharm Pharm Sci 2012; 4(4): 508-11.

40. Gulcin I, Kaya R, Goren AC, Akincioglu H, Topal M, Bingol Z, et al., Anticholinergic, antidiabetic and antioxidant activities of cinnamon (Cinnamomum verum) bark extracts: polyphenol contents analysis by LCMS/MS. International Journal of Food Properties 2019; 22(1): 1511-26.

41. Abd El Azim MH, El-Mesallamy AM, El-Gerby M, Awad A. Anti-Tumor, antioxidant and antimicrobial and the phenolic constituents of clove flower buds (Syzygium aromaticum). J Microb Biochem Technol 2014; 10: s8s007.

42. Oliveira I, Valentão P, Lopes R, Andrade PB, Bento A, Pereira JA.Phytochemical characterization and radical scavenging activity of Portulaca oleraceae L. leaves and stems. Microchem J 2009; 92(2): 129-34.

43. Daneshzadeh MS, Abbaspour H, Amjad L, Nafchi AM.
An investigation on phytochemical, antioxidant and antibacterial properties of extract from Eryngium billardieri F. Delaroche. Journal of Food Measurement and Characterization 2020;14(2):708-15..

44. Shalaby MT, Ghanem AA, Maamon HM. Protective effect of ginger and cactus saguaro extract against cancer formation cells. Journal of Food and Dairy Sciences 2016; 7(11): 487-91.

45. Martins N, Barros L, Santos-Buelga C, Silva S, Henriques M, Ferreira IC. Decoction, infusion and hydroalcoholic extract of cultivated thyme: Antioxidant and antibacterial activities, and phenolic characterisation. Food Chem 2015; 167: 131-7.

46. Jin KT, Lu ZB, Chen JY, Liu YY, Lan HR, Dong HY, et al., Recent trends in nanocarrier-based targeted chemotherapy: selective delivery of anticancer drugs for effective lung, colon, cervical, and breast cancer treatment. Journal of Nanomaterials 2020; 2020.

47. Hajebi S, Tabrizi MH, Moghaddam MN, Shahraki F, Yadamani S. Rapeseed flower pollen bio-green synthesized silver nanoparticles: A promising antioxidant, anticancer and antiangiogenic compound. J Biol Inorg Chem 2019; 24(3): 395-404.

48. Shahraki F, Tabrizi MH, Moghaddam MN, Hajebi S.Biogreen synthesis $\mathrm{ZnO}-\mathrm{NPs}$ in Brassica napus pollen extract: biosynthesis, antioxidant, cytotoxicity and proapoptotic properties. IET Nanobiotechnology 2019; 13(5): 471-6.

49. Nallamuthu I, Parthasarathi A, Khanum F. Thymoquinone-loaded PLGA nanoparticles: antioxidant and anti-microbial properties. International Current Pharmaceutical Journal 2013; 2(12): 202-7.

50. Pereira MC, Oliveira DA, Hill LE, Zambiazi RC, Borges $\mathrm{CD}$, Vizzotto M, et al. Effect of nanoencapsulation using PLGA on antioxidant and antimicrobial activities of guabiroba fruit phenolic extract. Food Chem 2018; 240: 396-404. 